\title{
Acquisition of a gene encoding mannose-resistant haemagglutinating fimbriae by a resistance plasmid during long-term urinary infection
}

\author{
BARBARA A. HALES* and S. G. B. AMYES + \\ Department of Bacteriology, The Medical School, University of Edinburgh, Teviot Place, Edinburgh EH8 9AG
}

\begin{abstract}
Summary. Urine was collected twice weekly from one patient during a 25-month period. Escherichia coli harbouring a resistance plasmid, pUK28, which confers trimethoprim, ampicillin, sulphamethoxazole, spectinomycin and streptomycin resistance was identified in the urine. Carriage of strains containing plasmid pUK28 was observed during three separate periods which totalled 16 months, even though the patient did not receive antibacterial drug therapy for most of that time. The plasmid was able to acquire the genes responsible for mannose-resistant haemagglutination and these genes were increasingly associated with the plasmid towards the end of the study period.
\end{abstract}

\section{Introduction}

Fimbriae aid the attachment to and colonisation of the gastro-intestinal tract by enteropathogenic Escherichia coli. The fimbrial antigens isolated from enteric $E$. coli obtained from cattle (K88), pigs (K99), and man (CFA/I and CFA/II) are genetically determined by plasmids (Ørskov and Ørskov, 1966; Smith and Linggood, 1972; Evans et al., 1975; Elwell and Shipley, 1980; Penaranda et al., 1980). However, bacteria persist in the gastrointestinal tract for only short periods (Hartley and Richmond, 1975) and the plasmids carried by these strains are equally short-lived (Amyes and Gould, 1984).

$E$. coli is also an important pathogen in urinarytract infections and these uropathogenic strains frequently possess fimbriae that mediate adherence of the bacteria to uroepithelial cells (Svanborg-Edén and Hansson, 1978). The presence of these fimbriae is detected by the ability of the bacteria to agglutinate human erythrocytes in the presence of $\mathrm{D}(+)$ mannose, termed mannose-resistant haemagglutination (MRHA) (Ljungh et al., 1979). The ability to attach to the mucosal surface of the urinary tract is thought to be necessary for bacterial colonisation and persistence (Svanborg-Edén et al., 1981). However, unlike the genes encoding fimbrial

Received 7 Feb. 1986; accepted 17 Mar. 1986.

* Present address: Department of Microbiology, University of Leicester, University Road, Leicester LE1 7RH.

† Correspondence should be addressed to Dr S. G. B. Amyes. antigens in enteropathogenic $E$. coli, the equivalent genes in uropathogenic $E$. coli have been shown to be located on the bacterial chromosome (Hull et al., 1981). Recently, we have demonstrated that these genes may be carried on plasmids and transferred between strains (Hales and Amyes, 1983).

In this paper we show that, during persistent urinary infection by $E$. coli, a gene encoding MRHA fimbriae became inserted into the resistance plasmid carried by the causative organism and survived for the duration of the infection.

\section{Materials and methods}

\section{Bacterial strains and plasmids}

The standard bacterial strains used were E. coli $\mathrm{K} 12$ strain $\mathrm{J} 53$ and the rifampicin-resistant strain $\mathrm{J} 62-2$ (Bachmann, 1972). The inc W plasmid Sa confers resistance to kanamycin, chloramphenicol, streptomycin and sulphamethoxazole (Ward and Grinsted, 1982). The inc A plasmid RAl, which confers resistance to tetracycline and sulphamethoxazole, was kindly supplied by $\operatorname{Dr} \mathrm{K}$. J. Towner.

\section{Haemagglutination}

Haemagglutination was assayed by the method of Svanborg-Edén and Hansson (1978), modified by growing the bacteria in Brain Heart Infusion Broth (BHI) (Oxoid) for $48 \mathrm{~h}$. The assay was performed separately with human (blood group A) and guinea-pig erythrocytes, in the presence and absence of $\mathrm{D}(+)$ mannose $2 \cdot 5 \%$. 


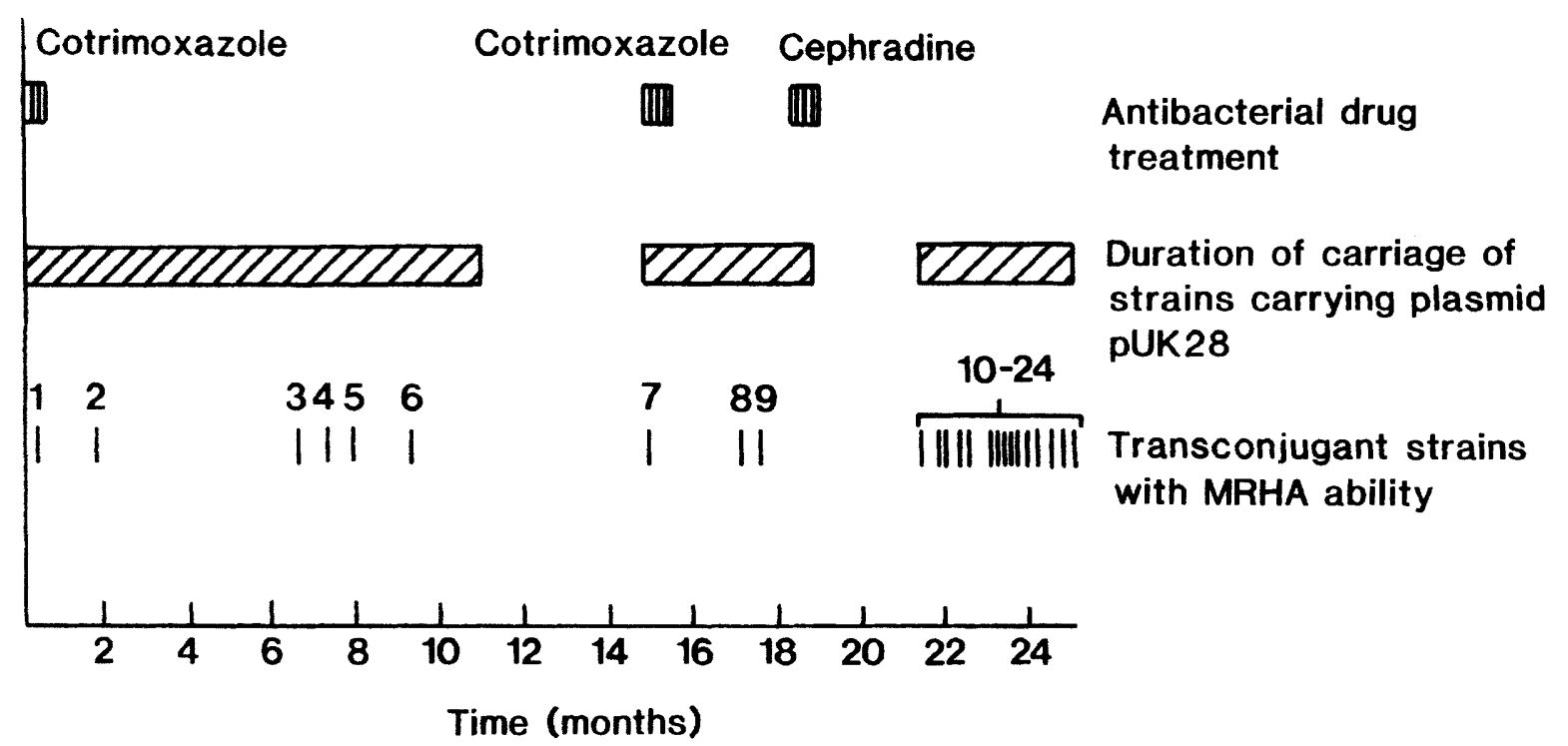

Fig. I. The survival of plasmid pUK28 during persistent urinary infection. Top line: courses of antibiotic treatment; middle line: persistence of the transferable plasmid pUK28 in the infecting bacteria: bottom line: the 24 occasions on which strains with MRHA ability that transferred with pUK28 into E. coli strain J62-2 were isolated are numbered accordingly.

\section{Plasmid transfer and incompatibility analysis}

Plasmid transfer was performed by the method of Smith (1969) as modified by Amyes and Gould (1984) but mating times were varied from $1 \mathrm{~h}$ to $18 \mathrm{~h}$ as indicated. Plasmid incompatibility was determined by the ability of the plasmid to transfer to $E$. coli K12 strains containing plasmids of known incompatibility groups and their ability to co-exist with those standard plasmids (Coetzee et al., 1972).

\section{Isolation and characterisation of plasmid DNA}

Plasmid DNA was extracted by the method of Birnboim and Doly (1979) and was separated by horizontal electrophoresis in $0.5 \%$ agarose gels.

\section{Determination of antibacterial drug resistance}

Overnight BHI broth cultures of bacteria were diluted $10^{4}$ times in minimal medium and spotted on to Diagnostic Sensitivity Test Agar plates (Oxoid). Antimicrobial drugs were incorporated into the agar at a concentration of $10 \mathrm{mg} / \mathrm{L}$. except for spectinomycin and sulphamethoxazole which were used at $100 \mathrm{mg} / \mathrm{L}$.

\section{Results}

\section{Isolation of strains}

An elderly female patient in the Astley Ainslie Hospital, Edinburgh was asked to participate in a long-term study. She was asked to give urine specimens twice-weekly, which she did for 2 years.
Initially she was receiving a short course of cotrimoxazole and the subsequent serial analysis of her urine specimens was initiated to observe the persistence of transferable trimethoprim resistance genes within urinary bacteria (Amyes, 1983).

During the initial 7-day course of cotrimoxazole, trimethoprim-resistant bacteria predominated in the urine (fig. 1). These organisms were incubated in mixed cultures with a rifampicin resistant $E$. coli J62-2 for $24 \mathrm{~h}$ to allow conjugation and the recipient strains were selected on trimethoprimcontaining medium. The recipient strain had acquired a single plasmid that conferred resistance to ampicillin, streptomycin, spectinomycin and sulphamethoxazole as well as trimethoprim. This plasmid was $74 \mathrm{~kb}$ in size and was called pUK28. It was classified in the $\mathrm{A}$ incompatibility group because it was unstable in bacterial strains containing plasmid RAl but stable in strains containing plasmids of all the other incompatibility groups.

Similar analysis was performed on each twiceweekly specimen and the same transferable plasmid persisted for over 10 months. During this time the patient did not receive any antimicrobial drug therapy because for most of this time the numbers of bacteria were $<10^{8}$ organisms/L. After this period bacteria were still isolated from the patient's urine but resistant strains could not be found.

After another 4 months the numbers of bacteria exceeded $10^{8}$ cells/ $\mathrm{L}$ and pus cells were found in the deposit. Because there had been no evidence of trimethoprim-resistant strains in the patient's urine, 
she was treated for 7 days with cotrimoxazole. Immediately after treatment was commenced, the bacteria in the urine were found to possess the same trimethoprim R-plasmid as had been found in the first 10 -month period. However, by the end of 7 days, the numbers of bacteria had fallen to a level that did not warrant further treatment. The trimethoprim-resistant bacteria persisted for a further 4 months, at which time they again began to reach significant numbers. As the patient was excreting bacteria which were resistant to both trimethoprim and ampicillin, she was treated with a 7-day course of cephradine. This cleared the urine of all bacteria. However, during the next 2 months insignificant numbers of sensitive bacteria were found and, at the end of this period, the same plasmid reappeared in the urinary bacteria and persisted until the end of the study.

\section{Identification of $\mathrm{MRHA}^{+}$transconjugants}

The persistence of the plasmid-containing strain, in the absence of any obvious selective pressure, suggested that some virulence factor was involved. The fact that the plasmid itself had persisted for so long suggested that this virulence factor may be carried on the plasmid. Therefore, 95 E. coli J62-2 transconjugant strains, taken at approximately regular stages throughout the 2-year study period, were examined for their MRHA ability.

Of these strains, 24 were MRHA positive $\left(\mathrm{MRHA}^{+}\right)$but they were not evenly distributed throughout the 25-month period (fig. 1). Sixty-five of the transconjugants were obtained during the first 19 months and only nine of these were MRHA $^{+}$. However, 15 of the 30 transconjugants obtained during the last 6 months of the study were $\mathrm{MRHA}^{+}$.

\section{Plasmid analysis of $M R H A^{+}$and $M R H A^{-}$strains}

Plasmid analysis of the $24 \mathrm{MRHA}^{+}$strains revealed that all contained a $75-\mathrm{kb}$ plasmid except for strains 22 and 24 which contained plasmids of 84 and $87 \mathrm{~kb}$ respectively. Four of the transconjugant strains contained a second plasmid of $100 \mathrm{~kb}$ in addition to the 75-kb plasmid (fig. 2). The size of the plasmids in the $\mathrm{MRHA}^{+}$strains appeared to be slightly larger than the equivalent plasmids in transconjugant strains which were $\mathrm{MRHA}^{-}$but the increase was not sufficient to account for the acquisition of all the DNA necessary. However, in view of the large size of the plasmid, any direct estimation of the increase in plasmid size would be far too inaccurate.

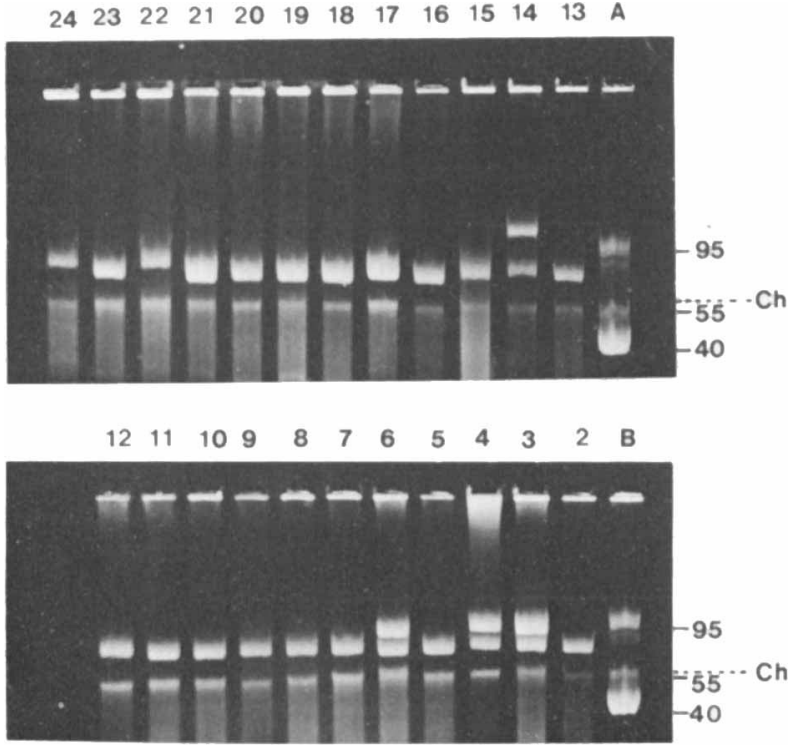

Fig. 2. Separation by agarose gel electrophoresis of plasmid DNA from $E$. coli strain $\mathrm{J62-2}$ transconjugants possessing $\mathrm{MRHA}^{+}$ability. The lane numbers refer to $\mathrm{MRHA}^{+}$transconjugants shown in fig. 1. Lanes $A$ and $B$ contain the standards plasmids R6K (40 kb), RP4 (55kb) and R1 (95kb). $\mathrm{Ch}=$ chromosomal DNA.

Removal of the MRHA gene into the smaller plasmid $S a$

The plasmid analysis suggested that the MRHA gene had become inserted into the plasmid, which may have resulted from transposition. To determine the size of fragment that was able to migrate, the MRHA gene was extracted from the plasmid from the clinical strains and inserted into the $I n c \mathrm{~W}$ plasmid, Sa, by the procedure shown (fig. 3). Plasmid Sa was introduced into eight $\mathrm{MRHA}^{+}$transconjugants $(1,2,3,6,7,9,10$ and 24$)$ during a $5-\mathrm{h}$ mating. Purified transconjugants from each of these matings were subcultured three times in $\mathrm{BHI}$ broth and then plated on to DSTA containing trimethoprim and kanamycin. Colonies from these plates were purified and then used as donors in a 1-h mating with $E$. coli $\mathbf{J} 53$ with selection made on kanamycin alone.

From each strain 70 transconjugants were spotted on to DSTA plates containing ampicillin, trimethoprim, chloramphenicol or kanamycin and DSTA without antibiotic. Transconjugant strains which were chloramphenicol- and kanamycinresistant but not trimethoprim- or ampicillinresistant were deemed to be those that contained the plasmid Sa but not the original clinical plasmid. The strains were purified and were assayed for their 


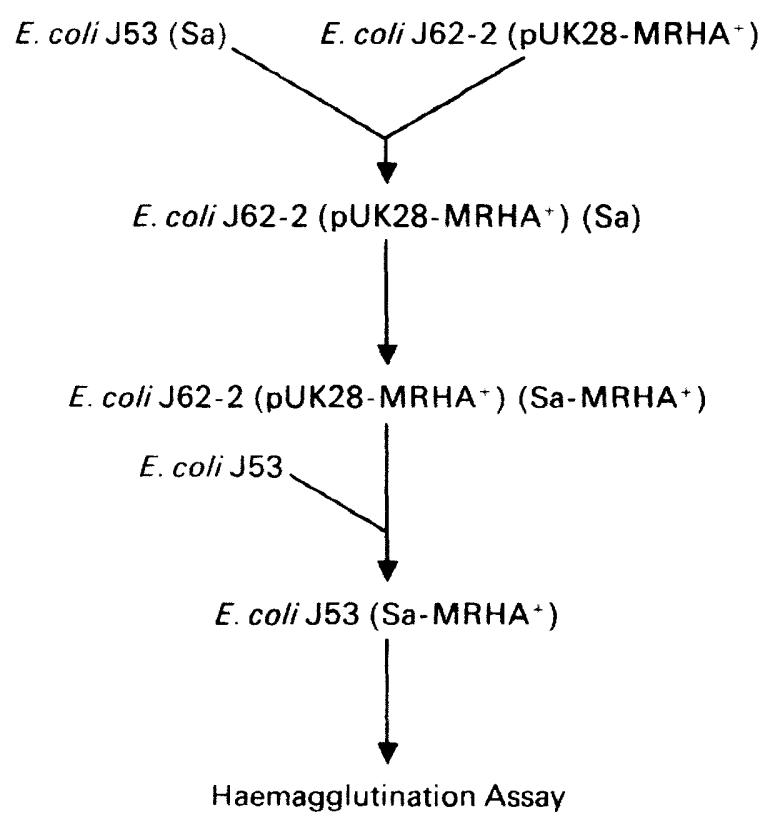

Fig. 3. Scheme for extraction of the MRHA gene from the clinical plasmid and insertion into plasmid $S a$.

haemagglutinating ability. Some of the J53 transconjugants, from six of the eight original strains tested, were MRHA ${ }^{*}$.

The plasmids from these $\mathrm{MRHA}^{-}$strains were extracted by alkaline lysis and compared with the native plasmid $\mathrm{Sa}$ by agarose gel electrophoresis. The size of plasmid Sa in the $\mathrm{MRHA}^{-}$strains was $44.4 \mathrm{~kb}$ compared with $35.2 \mathrm{~kb}$ for the native plasmid (fig. 4). The only exception was in strain 2 , the size of Sa was increased to $39 \cdot 4 \mathrm{~kb}$.

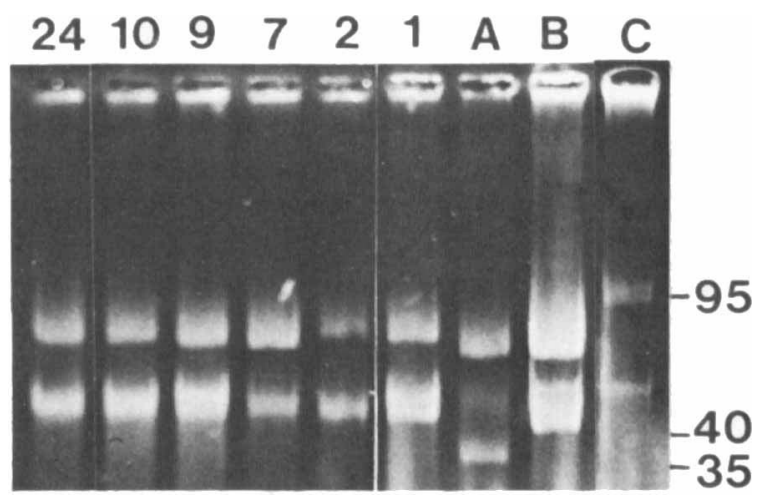

Fig. 4. Agarose gel electrophoresis showing the increase in size of the DNA of plasmid Sa after introduction of the MRHA gene. The lane numbers refer to plasmid DNA preparations of E. coli J53 (Sa) strains which have acquired the MRHA gene from the MRHA 'transconjugants shown in fig. $1 . \mathrm{A}=$ plasmid Sa ( $35 \mathrm{~kb}), B=$ plasmid $R 6 K(40 \mathrm{~kb}), C=$ plasmid $R 1(95 \mathrm{~kb})$.

\section{Discussion}

It has been believed traditionally that the withdrawal of the selection pressure of an antimicrobial drug will result in the eventual disappearance of resistant strains. In the highly competitive environment of the gastro-intestinal tract, this does indeed appear to be the case and resistant enterobacteria have been shown to be unable to persist, under normal circumstances, in the absence of drug selection pressure (Hartley and Richmond, 1975). We have also shown that $\mathrm{R}$-plasmid-containing strains are particularly short-lived and do not usually persist in the gastro-intestinal tract for longer than 4 days after the cessation of therapy (Amyes and Gould, 1984).

The persistence of the plasmid described in this paper suggests that the same situation may not pertain in the urinary tract. The lack of bacterial competition in this area would indicate that resistant strains should be able to survive longer after therapy has ended than they would in the gastrointestinal tract. However, R-plasmid-containing bacteria were found to persist 75 times longer than their gastro-intestinal counterparts and it seems unlikely that this would result solely from the lack of competition.

The establishment and persistence of urinary infections requires the ability of the bacteria to attach to uroepithelial cells (Svanborg-Edén et al., 1981). We have demonstrated that this ability may be plasmid-borne (Hales and Amyes, 1983). The results presented in this paper show that this plasmid also has the ability to acquire the genes necessary for MRHA. The longer the R-plasmid-containing strain had been exposed to the environment, the more often the plasmid was found with the MRHA genes present. It is likely that the original strains possessed the genes for MRHA and, during the course of the bacterial colonisation, copies of them were translocated to the plasmid. The acquisition of the MRHA genes was associated with a small change in the size of the plasmid. This change in size could not be measured directly. However, the plasmid was able to translocate these genes as readily as it was able to acquire them in the clinical setting. In the smaller plasmid, $\mathrm{Sa}$, it is much easier to determine the increase in size and the piece of DNA carrying the MRHA genes was about $8 \mathrm{~kb}$. The reason why this increase was not observed in all the J62-2 $\mathrm{MRHA}^{+}$transconjugants may be explained by the ability of some plasmids to lose redundant segments of DNA after the insertion of new genes (Barth et al., 1978). Thus, as in enteropathogenic E. coli (Echeverria and Murphy, 1980), 
uropathogenic strains are able to carry plasmids which confer virulence as well as antibacterial drug resistance.

In a separate study conducted at another hospital in Edinburgh, we have shown that this plasmid can be spectacularly successful (Amyes et al., 1986). In half of the bacteria responsible for significant bacteriuria and which possessed transferable trimethoprim resistance, this plasmid was present. Its domination reached a peak in 1982 and, since then, it has gone into decline. The success of this plasmid seems to result from three factors. First, it possessed the resistance determinants for the two drugs, cotrimoxazole and ampicillin, which dominate the treatment of urinary tract infections in this

\section{REFERENCES}

Amyes S G B 1983 The detection and incidence of transferable trimethoprim resistance. Health Bulletin (Edinburgh) 41: $100-107$.

Amyes S G B, Doherty C J, Young H-K 1986 Changes in highlevel trimethoprim resistance in hospital strains. In: Ishigami J (ed) Recent advances in chemotherapy, University of Tokyo Press, Tokyo, pp 403-404.

Amyes S G B, Gould I M 1984 Trimethoprim resistance plasmids in faecal bacteria. Annales de Microbiologie de l'Institut Pasteur 135B:177-186.

Bachmann B J 1972 Pedigrees of some mutant strains of Escherichia coli K-12. Bacteriological Reviews 36:525-557.

Barth P T, Grinter N J, Bradley D E 1976 Conjugal transfer system of plasmid RP4: Analysis by transposon 7 insertion. Journal of Bacteriology 133:43-52.

Birnboim H C, Doly J 1979 A rapid alkaline extraction procedure for screening recombinant plasmid DNA. Nucleic Acids Research 7:1513-1523.

Coetzee J N, Datta N, Hedges R W 1972 R factors from Proteus rettgeri. Journal of General Microbiology 72:543-552.

Echeverria P, Murphy J R 1980 Enterotoxigenic Escherichia coli carrying plasmids coding for antibiotic resistance and enterotoxin production. Journal of Infectious Diseases 142: 273-278.

Elwell L P, Shipley P L 1980 Plasmid-mediated factors associated with virulence of bacteria to animals. Annual Review of Microbiology 34:465-496.

Evans D G, Silver R P, Evans D J, Chase D G, Gorbach S L 1975 Plasmid-controlled colonization factor associated with virulence in Escherichia coli enterotoxigenic for humans. Infection and Immunity 12:656-667.

Hales B A, Amyes S G B 1983 The genetic carrier of bacterial attachment. Journal of Pharmacy and Pharmacology 35 Suppl:50p area. Second, the plasmid is a member of an unusual incompatibility group and this can only promote its passage through the Enterobacteriaceae as it is unlikely that it will be in competition with plasmids which are already resident in the new host. Third, the results of this paper show that the plasmid can persist for a long period in the absence of selective pressure and is able to acquire genes to aid colonisation and persistence.

\begin{abstract}
We thank the Biomedical Research Committee of the Scottish Home and Health Department (grant no. K/MRS/50/C492) for funding this work, Mrs Judyth Drysdale for the collection of the strains, and Mrs Catherine Doherty and Mrs Gillian Harris for excellent technical assistance.
\end{abstract}

Hartley C L, Richmond M H 1975 Antibiotic resistance and survival of $E$. coli in the alimentary tract. British Medical Journal 4:71-74

Hull R A, Gill R E, Hsu P, Minshew B H, Falkow S 1981 Construction and expression of recombinant plasmids encoding Type 1 or D-mannose-resistant pili from a urinary tract infection Escherichia coli isolate. Infection and Immunity 33: 933-938

Ljungh A, Faris A, Wadström T 1979 Hemagglutination by Escherichia coli in septicemia and urinary tract infections. Journal of Clinical Microbiology 10:477-481.

Ørskov I, Ørskov F 1966 Episome-carried surface antigen K88 of Escherichia coli I. Transmission of the determinant of the K88 antigen and influence on the transfer of chromosomal markers. Journal of Bacteriology 91:69-75.

Penaranda M E, Mann M B, Evans D G, Evans D J 1980 Transfer of an ST:LT:CFA/II plasmid into Escherichia coli $\mathrm{K} 12$ strain RR1 by contransformation with pSC301 plasmid DNA. FEMS Microbiology Letters 8:251-254.

Smith H W, Linggood M A 1972 Further observations on Escherichia coli enterotoxins with particular regard to those produced by atypical piglet strains and by calf and lamb strains: the transmissible nature of these enterotoxins and of a $\mathrm{K}$ antigen possessed by calf and lamb strains. Journal of Medical Microbiology 5:243-250.

Smith J T 1969 R-factor gene expression in gram-negative bacteria. Journal of General Microbiology 55:109-120.

Svanborg-Edén C, Hagberg L, Hanson L A, Korhonen T, Leffler H, Olling S 1981 Adhesion of Escherichia coli in urinary tract infection. Ciba Foundation Symposium 80: $161-187$.

Svanborg-Edén C, Hansson H A 1978 Escherichia coli pili as possible mediators of attachment to human urinary tract epithelial cells. Infection and Immunity 21:229-237.

Ward J M, Grinsted J 1982 Physical and genetic analysis of the inc-W group plasmids R388, Sa and R7K. Plasmid 7:239 250 . 